\title{
Bitki Probiyotik Bakteriler: Bitkiler Üzerindeki Rolleri ve Uygulamalar
}

\section{Çiğdem Küçük ${ }^{1}$}

\begin{abstract}
ÖZET
Artan nüfus dolayısıyla hayvansal ve bitkisel besin maddelerine karşı yüksek talep, toprak verimliliğinin korunması üzerine endişelerin artması sonucu kimyasal gübrelere alternatif arayışları başlatmıştır. Bitki probiyotik bakteriler, kimyasal gübrelerin kullanımını azaltarak, çevre korunmasına odaklanmıştır. Bitki probiyotik bakteriler, gelişmeyi teşvik eden ve kök bölgesinde kolonize olan toprak bakterileridir. Bitkinin bitki probiyotik bakterilerin belirli suşları ile aşılanması, bitkinin kök ve sürgünlerin gelişimi üzerine doğrudan etki etmektedir, biyokütle üretimini arttırmaktadır. Bu bakteriler ayrıca, ürün kalitesinin artmasına da yardımcı olmaktadırlar. $\mathrm{Bu}$ nedenle, bitki probiyotik bakteriler olarak adlandirılan bu mikroorganizmalar, biyogübre olarak kullanımları ile dünya nüfusunun sürdürülebilmesi için gıda ve yemin üretimine katkıda bulunacak çevre dostu olarak tanımlanmışlardır. Bu derlemede, bitki probiyotik bakteriler olarak rizobakterilerin bitki gelişimi üzerindeki mekanizmaları özetlenmiştir.
\end{abstract}

MAKALE GEÇMİşi

Geliș 05 Aralık 2018

Kabul 30 Ocak 2019

\section{ANAHTAR}

KELIMELER

Bitki probiyotik bakteriler, biyogübre, bitki gelişimini teşvik, aktif mekanizmaları

\section{Plant Probiotic Bacteria: Their Role on Plants and Applications}

\begin{abstract}
Due to the increasing population, high demand against animal and vegetable nutrients has started to search for alternatives to chemical fertilizers as a result of increasing concerns about conservation of soil fertility. Plant probiotic bacteria, it is focused on protecting the environment, reducing the use of chemical fertilizers. Plant probiotic bacteria are soil bacteria that promote growth and colonize in the root zone. Inoculation of the plant with certain strains of plant probiotic bacteria has a direct effect on the growth of the plant's root and shoots, which increases biomass production. These bacteria also help to improve product quality. For this reason, these microorganisms called plant probiotic bacteria, are defined as environmentally friendly, which will contribute to the production of food and feed in order to sustain the world population with their use as biofertilizer. In this review, the mechanisms of rhizobacteria as plant probiotic bacteria on plant growth are summarized.
\end{abstract}

\author{
ARTICLE HISTORY \\ Received \\ 05 December 2018 \\ Accepted \\ 30 January 2019
}

\section{KEY WORDS \\ Plant probiotic bacteria, biofertilizer, promoting plant growth, active mechanisms}

\section{Giriș}

Günümüzde, artan nüfusun gıda ihtiyacını karşılamak için yapılan yoğun tarımsal işlemler; zararlı ve hastalıkları arttırdığından pestisid kullanımını teşvik etmiş, daha fazla verim almak için kimyasal gübrelerin kullanımını artırmıştır. Hem pestisid hem de kimyasal gübrelerin kullanımı canlıların sağlı̆̆ını olumsuz etkilemekte, ekosistemleri kirleterek yüzey suyu ve/veya yeraltı su kaynaklarında birikmektedir. Dünya nüfusunun 2050 yılında yaklaşık 9.5 milyara

\footnotetext{
${ }^{1}$ Harran Üniversitesi, Fen Edebiyat Fakültesi, Biyoloji Bölümü, Şanlıurfa

* Correspondence: ckucuk@harran.edu.tr
} 
ulaşacağı tahmin edildiğinden [1], yüksek verimli, biyotik ve abiyotik streslere karşı daha dirençli ürünler yetiştirmek için çevre ile dost yeni uygulamaların bulunması zorunlu hale gelmiştir [2]. Diğer yandan gelişmiş ve gelişmekte olan ülkelerde daha yüksek kaliteli ve sağlıklı gıdalara olan talep artış göstermiştir [3]. Bu anlamda, mikroorganizmaların özellikle bakterilerin, bitki gelişimini teşvik ediciler olarak bitki probiyotiklerinin birlikte kullanılması, pestisid ve kimyasal gübre kullanımının azaltılmasını sağlayarak, bitkisel verimin arttırılması ve daha kaliteli ürünlerin elde edilmesine imkan vermiştir $[3,4]$. Bitki probiyotik bakteri terimi ilk kez Haas ve Keel [5] tarafından bitkilerin yararlandığı bir grup mikroorganizma için tanımlanmıştır. $\mathrm{Bu}$ organizmalar için üç temel kriter belirlenmiştir; bunlar; i) rhizosfer kolonizasyonunda etkinlik ve rekabet gücü, ii) konakçılarında indüklenmiş sistemik (ISR) direnç oluşturma, iii) patojenler üzerine doğrudan antagonistik özellik göstermeleridir. Kloepper ve Schrot [6] ise daha önce bu bakterileri, bitki gelişimini teşvik eden rizobakteriler (PGPR) olarak adlandırmıştır. PGPR, bitkilerin çeşitli yollardan üretkenliklerini, bağışıklıklarını iyileştirme yeteneğine sahip olan, doğal olarak bulunan toprak bakterileridir. $\mathrm{Bu}$ toprak bakterileri bitki rizosferinde bulunur [6].

Bitki probiyotik bakterileri; ana bitki ile etkileşimlerine göre iki gruba ayrılarak sınıflandırılmıştır; (i) bitki hücreleri dışında yaşayan ve rizosfere saldıkları metabolitlerin bir sonucu olarak bitki büyümesini arttıran serbest yaşayan rizobakteriler ve (ii) bitki dokularında ve/veya hücrelerinde yaşayan, kendi metabolizmasını doğrudan konakçı bitkiyle değiştiren ve bitki gelişimlerini olumlu yönde etkileyen endofitlerdir [7]. Endofitik bakterilerin çoğu, konakçı bitkinin hücreler arası alanlarında yaşar; bununla birlikte, konakçıları ile tamamen karşılıklı etkileşimler oluşturabilen ve içinde bulunduğu bitki hücresine nüfuz edebilen bazı bakteriler vardır. Bu bakteriler bitki hücreleri içinde bakteriyel farklılaşma sürecinden geçerek özel yapıların oluşmasına neden olurlar. En iyi bilinen simbiyotik bakteriler, baklagiller ile simbiyotik bir ilişki kuran atmosferik azotu fikse edebilen Rhizobium bakterilerdir. $\mathrm{Bu}$ bakteriler genel olarak kök nodülleri olarak adlandırılan özel bir kök yapısı oluştururlar [8]. Bakteriyel azot fiksasyonunun gerçekleştiği Alnus ağaçları gibi aktinorhizal bitkilerde nodüllerin oluşumunu indükleyen Frankia [9], siyanobakteriler ve sikadlar arasındaki simbiyoz, diğer simbiyotik ilişkilere örnek olarak verilebilir [10].

Yapılan birçok çalışmada, bitki probiyotik bakteriler ve bitki gelişimini teşvik eden bakterilerin biyogübre olarak kullanımının bitkisel üretim ve toprak verimliliğinin artışına katkıda bulunduğu açıklanmıştır $[1,11,12]$. Bitkilerin gelişimi ve verimini iyileştiren bir veya birkaç bakteri formülasyonunu içeren bakteriyal biyogübreler son yıllarda artış göstermiştir. $\mathrm{Bu}$ 
bakterilerin; topraklardaki besinleri bitkilerin kullanabileceği forma dönüştürerek, bitkilerin besin maddelerine erişimini artırma yoluyla besin alımını etkilediği bildirilmiştir [13]. Bununla birlikte, bu bakterilerin fitohormon biyosentezi, çevresel stresleri azaltma veya önleme mekanizmaları ile patojenlerin neden olduğu bitki hastalıklarının önlenmesi gibi bitki gelişimini desteklemek için farklı mekanizmalara sahip oldukları açıklanmıştır [13]. Bu derlemede, bitki probiyotik bakterilerinin bitkiler üzerinde etkili olan mekanizmaları, bitkisel verimi artıran çeşitli bakteri izolatları ile yapılan potansiyel uygulamalar özetlenmiştir.

\section{Bitki Gelişimini Teşvik Mekanizmaları}

Rizobacteriler, aşağıda verilen etki mekanizmalarına göre gruplandırılabilen geniş bir mekanizma yelpazesi aracılığıyla bitki gelişimini destekleyebilmektedir; (i) doğrudan bitkiler tarafindan asimile edilebilen maddelerin sentezi, (ii) besinlerin mobilizasyonu, (iii) bitki stres direncinin indüklenmesi, (iv) bitki hastalıklarının önlenmesidir [1]. Bitki gelişimini teşvik edici özelliklere sahip bazı bakteriler Tablo 1'de verilmiştir.

Tablo 1. Bazı bitki probiyotik bakteriler ve bitki gelişimini teşvik mekanizmaları

\begin{tabular}{|c|c|c|c|}
\hline $\begin{array}{c}\text { Bitki gelişimini } \\
\text { teşvik eden } \\
\text { özellikleri } \\
\end{array}$ & Bitki probiyotik bakteriler & Konukçu Bitki & Kaynak \\
\hline \multirow{6}{*}{$\begin{array}{c}\text { Azot } \\
\text { fiksasyonu }\end{array}$} & Azotobacter sp. & çeşitli tahıllar, tütün,çay & [14] \\
\hline & Bacillus sp. & çeltik & {$[15]$} \\
\hline & Frankia sp. & Alnus cinsi ağaçlar & [9] \\
\hline & Rhizobium spp. & baklagiller & [16] \\
\hline & Pseudomonas sp. & çeltik & [15] \\
\hline & Herbaspirillum $\mathrm{sp}$ & sorghum, misır, fasulye & {$[15]$} \\
\hline \multirow{8}{*}{$\begin{array}{c}\text { Fosfat } \\
\text { çözünümü }\end{array}$} & B.megaterium var. phosphaticum & buğday, çeltik & {$[17]$} \\
\hline & B.subtilis & buğday & [18] \\
\hline & B.circulans & buğday & [19] \\
\hline & Rhizobium sp. & misir & [19] \\
\hline & Bacillus sp. & çilek & {$[20]$} \\
\hline & Micrococcus sp. & domates & {$[20]$} \\
\hline & Pseudomonas sp. & domates & {$[18]$} \\
\hline & Flavobacterium sp. & marul & {$[20]$} \\
\hline \multirow{3}{*}{$\begin{array}{l}\text { Potasyum } \\
\text { çözünümü }\end{array}$} & Bacillus sp. & sudan otu, misir & [19] \\
\hline & Paenibacillus sp. & biber & [19] \\
\hline & Pseudomonas sp. & tütün & [21] \\
\hline \multirow{4}{*}{$\begin{array}{c}\text { Çinko } \\
\text { çözünümü }\end{array}$} & Rhizobium sp. & çeltik & {$[22]$} \\
\hline & Azospirillum sp. & buğday & {$[22]$} \\
\hline & B.megaterium & buğday & {$[22]$} \\
\hline & B.subtilis & buğday & {$[22]$} \\
\hline \multirow{3}{*}{$\begin{array}{c}\text { Biyolojik } \\
\text { kontrol }\end{array}$} & Bacillus sp. & misir & {$[12]$} \\
\hline & Bacillus sp. & domates & {$[12]$} \\
\hline & Bacillus sp. & hiyar & {$[12]$} \\
\hline
\end{tabular}




\begin{tabular}{|l|l|c|l|}
\hline & Bacillus sp. & biber, buğday & {$[23]$} \\
\cline { 2 - 4 } & Paenibacillus & $\begin{array}{c}\text { domates, biber, buğday, } \\
\text { arpa }\end{array}$ & {$[24]$} \\
\cline { 2 - 4 } & Pseudomonas sp. & $\begin{array}{c}\text { pamuk, misır, çeltik, hiyar, } \\
\text { domates }\end{array}$ & {$[5]$} \\
\cline { 2 - 4 } & Streptomyces sp. & kakao & {$[25]$} \\
\hline
\end{tabular}

\section{Moleküllerin ve Maddelerin Asimilasyon ve/veya Biyosentezi}

\section{Bitki probiyotik bakteriler ve azot fiksasyonu}

Yeryüzünde oldukça bol olmasına rağmen, bitkiler için azot $(\mathrm{N})$; aminoasitlerin oluşumu ve daha sonra proteinler için gerekli olan besin maddesidir. Bazı prokaryotlar, atmosferik azotun organik formlara kombine edilmesi veya dönüştürülmesi sürecini yönetmekte, bu da nihayetinde bitkiler tarafından asimile edilebilmektedir $[14,15]$. Serbest yaşayan rizobakteriler arasında Azospirillum, Azotobacter, Beijerinckia, Bacillus, Paenibacillus, Burkholderia, Gluconoacetobacter ve Herbaspirillum türlerinin üyeleri azot fikse edici mikroorganizmalar olarak rapor edilmiştir [15]. Azospirillum cinsi genellikle 1lıman bölgelerdeki hububatlar ile ilişkili olup ayrıca bazı baklagillerde ve şeker kamışlarında bitki verimini arttırmıştır [15, 26, 27]. Azotobacter'in bazı izolatları buğday, arpa, yulaf, çeltik veya mısır gibi çeşitli tahıllar için biyogübre olarak test edilmiş; ayçiçeği, domates, pancar, tütün, çay, kahve ve hindistan cevizi gibi diğer bitki türlerinde de etkinlikleri belirlenmiştir [15, 28]. Gluconacetobacter, Azospirillum ve Herbaspirillum cinslerine ait bazı türler şeker kamışı bitkisinin endofitleri olarak bitki beslenmesinde rol oynayan azot fiksatörleri olarak hareket etmişlerdir [14, 29]. Bacillus ve Paenibacillus cinslerinin serbest yaşayan azot fikserleri olduğu tespit edilmiş, bu da onları biyogübre olarak uygulama için uygun adaylar haline getirmiştir [17, 30]. Üstelik, serbest yaşayan bu bakterilerin bazıları; çeltik köklerinde Azoarcus, Azospirillum ve Burkholderia'nın bazı suşları ile buğday bitkilerinde Azorhizobium suşları bitki köklerinde gelişme göstererek ürün ve bitkilerdeki azot konsantrasyonunu artırmıştır [29]. Ayrıca, çeltik ve buğday kökleri ile ilişkili olarak bulunan Rhizobium ve Bradyrhizobium cinslerinin bazı suşları, bitki verimini ve bitkilerin besin konsantrasyonunu arttırmıştır [22]. Diğer yandan, bazı diazotropik bakteriler, esas olarak kök nodüllerinin oluşumu yoluyla bitki dokuları içinde karşılıklı olarak simbiyoz kurabilmektedir. Bu simbiyozlar Rhizobium ile baklagiller, Frankia ile aktinorhizal bitkiler ve siyanobakteriler ile sikadlar arasında bulunmaktadır $[10,15]$. 


\section{Bitki probiyotik bakteriler tarafindan fitohormon biyosentezi}

Birçok bakteriyel endofit, bitki büyümesinin ve gelişiminin farklı aşamalarındaki çeşitli süreçlerde yer alan organik moleküller olarak tanımlanan fitohormonları sentezleyebilmektedir [31]. Bu fitohormonların bazı mikroorganizmalar tarafindan biyosentezi bitki patojenezinde rol oynayabilmiş; bitki gelişimini teşvik edici özellikler olarak bitki büyüme ve gelişmesine katkıda bulunmuştur [32].

Oksinler, bazıç bakteriler tarafından üretilen fitohormonlar olup, bakteriyel iletişim için anahtar sinyal moleküller olarak tanımlanmıştır [31]. Oksinler arasında indol-3-asetik asit (IAA), bitkilerde en iyi bilinen ve en aktif oksin'dir. Gibberellinler tohum çimlenmesinde, kök ve yaprak büyümesi, çiçek indüksiyonu, çiçek ve meyve gelişiminde; etilen ise meyve olgunlaşması, çiçek açması veya yaprak dökülmesi gibi çeşitli süreçlerin düzenlenmesinde etkili olan bitki hormonlarıdır. Bununla birlikte, tohum çimlenmesi, ikincil kök oluşumu ve kök-saç uzamasını da teşvik etmişlerdir [31]. Bu fitohormonların hepsi bitki probiyotik rizobakterileri tarafından sentezlenmiştir [32, 33]. Oksin üreten Bacillus spp.'in, patates (Solanum tuberosum) veya çeltik (Oryza sativa) gibi bazı bitkilerin gelişiminde olumlu bir etki yarattığı bildirilmiştir [31, 34]. Bacillus cinsinin bazı üyeleri sitokinin üreticileri olarak tanımlanmıştır [31, 35]. Bacillus megaterium ve Azotobacter chroococcum suşlarının sitokinin ürettiği ve hıyar büyümesini desteklediği tespit edilmiştir [36]. Liu ve ark. [35], sitokinin üreten Bacillus subtilis suşları ile aşılanmış mazı fidelerinin kuraklık stresine karşı dirençli olduğunu saptamışlardır. Bazı Paenibacillus suşları da iyi birer fitohormon üreticisi olarak rapor edilmiştir [30]. Bent ve ark. [37] tarafından yapılan bir çalışmada Paenibacillus polymyxa'nın bir suşu ile aşılanmış çam (Pinus contorta) fideciklerinin köklerinde yüksek oranda IAA düzeyi belirlenmiştir. Paenibacillus cinsinin pirinç, arpa ve buğday bitkileri için fitohormon üreticisi olarak etkinlikleri tespit edilmiştir [34, 38]. Enterobacter, Serratia nematodiphila, Sphingomonas sp., Serratia marcescens suşları da iyi birer fitohormon üreticisi olarak saptanmış, şeker kamışı, buğday, biber ve soya fasulyesi ile muamele edildiğinde ürün verimlerini arttırmışlardır [27, 39, 40]. Rhizobium cinsi bakteriler de fitohormon sentezleyicileri olarak tanımlanmıştır. IAA üreten rhizobial suşlar, biber (Capsicum annuum), domates (Solanum lycopersicum), çilek (Fragaria anannasa), kırmızı karanfil (Dianthus caryophyllus), marul (Lactuca sativa) ve havuç (Daucus carota) gibi birçok ürünün gelişimini teşvik etmiştir [41, 42]. Nil deltasındaki tarlalardan izole edilen Rhizobium leguminosarum suşlarının, IAA üretiminin yanı sıra, oksin ve gibberellin üreticileri olduğu incelenmiştir [43]. Sphingomonas cinsi de fitohormon üreten bakteriler olarak rapor edilmiş; gibberellin üreten Sphingomonas sp. 
LK11 suşu ile muamele edilen yoncanın gelişimi önemli ölçüde artmıştır [44]. Asaf ve ark. [39] soya fasulyesi gelişiminde; Sphingomonas ve Serratia suşları tarafindan salgılanan fitohormonların olumlu etkisini açıklamışlardır. Fitohormon üretici bitki probiyotik bakterilerin bazısı, konukçuları ve ürettikleri fitohormonlar Tablo 2'de verilmiştir.

Tablo 2 Fitohormon üreten bazı bakteriler ve konukçuları

\begin{tabular}{|c|c|c|c|}
\hline Bakteri & Fitohormon & Bitki & Kaynak \\
\hline Bacillus subtilis & Indol asetik asit (IAA) & Soya fasulyesi & {$[45]$} \\
\hline Streptomyces acidiscabies & Siderofor & Yem bezelyesi & [46] \\
\hline Enterobacter sp. & IAA & Burçak & [40] \\
\hline Spingomonas sp. LK11 & $\begin{array}{l}\text { IAA, } \\
\text { gibberellin }\end{array}$ & Domates & {$[47]$} \\
\hline Sinorhizobium meliloti & ACC-deaminaz & Yonca & [44] \\
\hline Pseudomonas sp. & ACC-deaminaz & Buğday & [48] \\
\hline Serratia sp. & ACC-deaminaz & Buğday & [49] \\
\hline Pseudomonas sp. & ACC-deaminaz & Buğday & [49] \\
\hline Spingomonas sp. TP1 & $\begin{array}{l}\text { Jasmonik asit, } \\
\text { IAA, } \\
\text { gibberellin }\end{array}$ & Soya fasulyesi & [39] \\
\hline Serratia marcescens & IAA & Soya fasulyesi & {$[39]$} \\
\hline Bacillus subtilis TP5 & IAA & Çam & [37] \\
\hline $\begin{array}{l}\text { Stenotrophomonas chelatiphaga } \\
\text { LPM-5 }\end{array}$ & Siderofor & Misır & {$[50]$} \\
\hline $\begin{array}{l}\text { Stenotrophomonas chelatiphaga } \\
\text { LPM-5 }\end{array}$ & Siderofor & Kanola & {$[50]$} \\
\hline $\begin{array}{l}\text { Micrococcus yunnanensis YIM } \\
65004\end{array}$ & Siderofor & Misır & {$[50]$} \\
\hline $\begin{array}{l}\text { Micrococcus yunnanensis YIM } \\
65004\end{array}$ & Siderofor & Kanola & {$[50]$} \\
\hline
\end{tabular}

Bazı bakteriler, bitkilerde etilen oluşumunu hidrolize etmek için ACC deaminaz (1aminosiklopropan-1-karboksilat deaminaz) üretmektedir. Bu nedenle, bu bakteriler bitkilerde etilen seviyelerini düzenleyerek yüksek etilen konsantrasyonlarının olumsuz etkilerinin bir kısmını önlemişlerdir [51]. Ayrıca bu moleküllerin Rhizobium sp. ve baklagil arasındaki nodülasyon oluşumunda da önemli bir role sahip olduğu açıklanmıştır [16]. Rhizobium bakterileri arasında ACC deaminaz üretimi yapan birçok suş belirlenmişstir. Rhizobium leguminosarum suşları ACC deaminaz üretimleri ile biber ve domates bitkisinin gelişimlerini arttırmıştır [16]. Ekzojen bir acdS genini (ACC deaminaz geni) ifade eden Ensifer meliloti suşu, yoncanın bitki gelişimini arttırmıştır [44]. Mesorhizobium suşundaki acdS geninin eksojen ekspresyonu, tuz stresinde nohut bitkilerinin gelişimini teşvik etmiştir [52]. Çok sayıda rizobiyal türlerin ACC deaminaz üretebildiği tespit edilmesine rağmen, Pseudomonas cinsinin 
bu özel molekülün ilk üreticisi olduğu bildirilmiştir [53]. Shaharoona ve ark. [54], ACC deaminaz içeren iki Pseudomonas suşunun, değişen NPK besin düzeyleri ile buğday bitkilerinin gelişimlerini ve verimlerini artırdığını bildirmişlerdir. Magnucka ve Pietr [48], ACC üreten çeşitli Pseudomonas suşlarının buğday fidelerinin büyümesinde etkili rol oynadıklarını bildirmişlerdir. Zerrouk ve ark. [55] hurma rizosferinden izole edilen bir Pseudomonas suşunun gelişiminin, hem tuz hem de alüminyum stresi altında etkilenmediğini, mısır bitkileri ile aşılanması sonucunda bitkinin iki farklı stres altında da gelişmesini teşvik ettiğini bildirmişlerdir. Tuz stres koşulları altında Rhizobium ve Pseudomonas 'ın ACC deaminaz üreten suşları, fasulyenin gelişimi, fizyolojisi ve kalitesinde önemli oranda artış sağlamış; Serratia ve Pseudomonas' 1n ACC deaminaz üreten suşları ise buğday bitkilerinin verimini artırmıştır [49]. Suarez ve ark. [56], tuzlu topraklarda Hartmannibacter diazotrophicus'un ACC deaminaz üreten bir suşu ile muamele edilen arpada (Hordeum vulgare), bitki gelişiminin arttığını tespit etmişlerdir.

\section{Bitki probiyotik bakteriler ve besin seferberliği}

Fosfor (P), bitkiler için ikinci temel besin maddesidir, topraklarda çözünürlülüğü oldukça güçtür ve buna bağlı olarak, bu element, tarımda kimyasal fosforlu gübreler olarak topraklara ayrıca ilave edilmektedir. Bununla birlikte, ekim alanlarına gübre olarak uygulandığında da, fosfor hızla çözünmez hale gelir ve bu nedenle bitkiler için kullanılımı oldukça zordur [20]. Bu nedenle, P çözücü bakterilerin kullanımı, çevreye zarar veren kimyasal P'lu gübrelerin kullanımlarının azaltılması açısından önemlidir. Micrococcus, Pseudomonas, Bacillus, Paenibacillus, Deftia, Azotobacter, Klebsiella, Pantoea ve Flavobacterium cinsleri gibi toprak bakterilerinin etkili fosfat çözücü oldukları bildirilmiştir [57]. Havuç, arpa, şeker pancarı, marul, çilek, süs bitkileri ve baklagiller gibi bazı ürünlerin gelişimini teşvik eden birçok fosfat çözücü rizobiyal suş bulunmuştur [20, 21, 58, 59]. Garcia-Fraile ve ark. [1], fosfat çözen ve biber ile domates bitkilerinin gelişimini teşvik eden iki Rhizobium leguminosarum suşunu tespit etmişlerdir. Panda ve ark. [58] çeşitli bitkilerden Bacillus, Pseudomonas, Micrococcus, Staphylococcus, Microbacterium ve Delftia cinslerine ait suşlar izole etmişler ve bu suşların da antagonistik özelliklere sahip olduklarını göstermiştir. Streptomyces spp. buğday bitkileri için de fosfor çözücü olarak tanımlanmıştır [20].

Azot ve fosfordan sonra, potasyum (K) bitki büyümesi için gerekli olan üçüncü besindir. Bazı rizobakterilerin çözünmez potasyum formlarını kullanılabilir hale getirebildikleri incelenmiştir [18]. K çözücü bakteriyel cinslerin çeşitliliği oldukça fazla bulunmuştur [19]. En fazla sayıda 
K çözücü olarak Bacillus ve Paenibacillus cinsleri belirlenmiştir. Bacillus edaphicus'un buğdaydaki potasyum alımını arttırdığı bildirilmiştir [19], Paenibacillus glucanolyticus ise karabiber kuru ağırlığını arttırmıştır [60]. Potasyum çözücü Bacillus mucilaginosus ile aşılanmış sudan otu daha yüksek verime sahip olmuştur [19]. Laboratuvar koşullarında K çözücü Bacillus mucilaginosus ile aşılanmış buğday ve mısır bitkilerinin yapraklarında klorofil içeriği ve bitki biyokütlesi artmıştır [19]. Pseudomonas cinsinin bir suşu, çay bitkisinin [21] ve tütünün [61] gelişmesini arttıran K çözücü olarak tanımlanmıştır. Zhang ve Kong [61] çalışmalarında; tütün bitkileri üzerinde olumlu etkisi olan bir Actinobacteria olan Microbacterium foliorum cinsine ait bir K çözücü tür bulmuşlardır.

\section{Bitki probiyotik bakteriler tarafından siderofor üretimi}

Sideroforlar, demirin $\left(\mathrm{Fe}^{+3}\right)$ çevreden taşınmasında görevli olan organik bileşiklerdir [62]. $\mathrm{Fe}^{+3}$ 'in bitkilere sınırlayıcı olduğu durumlarda, toprak mikroorganizmalarından elde edilen bileşikler bu sorunu gidermektedir [62]. Endofitik Streptomyces suşlarından elde edilen sideroforlar ve IAA ile, neem ağacı (Azadirachta indica) ve kakao bitkisinin gelişmesini desteklemiştir [47, 63]. Siderofor üretebilen rhizobial suşlar, potansiyel biyogübreler olarak rapor edilmiş, havuç, marul, biber, domates, çilek, kırmızı karanfil ve nohut üretimini artırmışlardır [63]. Bir siderofor üretici olan Phyllobacterium endophyticum PEPV15, çileklerin gelişimini ve kalitesini arttırmıştır [4]. Ghavami ve ark. [50]; kanola (Brassica napus) rizosferinden Micrococcus ve Stenotrophomonas cinslerine ait çeşitli suşları izole etmişlerdir, bu suşların bazılarının sera koşullarında mısır ve kanola bitkisinin gelişimini aşısız olanlara oranla arttırdıklarını rapor etmişlerdir. Karagöz ve ark. [64] tarafından alkali ve asidik topraklardan 95 bakteri suşu izole edilmiş, suşlardan 5'inin azotu fikse edebildiği, siderofor üretebildiği ve fosfatı çözebildiği saptanmıştır.

\section{Bitki probiyotik bakteriler tarafından bitkilere strese karşı direnç kazandırılması}

Kuraklık, aşırı yağışın neden olduğu taşkınlar, aşırı sıcaklıklar veya tuzluluk, ağır metal kaynaklı fitotoksisite ve oksidatif stres gibi durumlardan kaynaklanan abiyotik stres, dünya çapında ürün kaybının başlıca nedenidir [65]. Liddycoat ve ark. [66], sera koşullarında su stres koşullarında üretilen kuşkonmaz tohumunun çimlenme ve fide gelişimini arttıran Pseudomonas suşlarını tespit etmişlerdir.

P.fluorescens MSP-393 suşu, tuzlu topraklarda yetiştirilen birçok ürünün gelişimini olumlu etkilemiş, P.putida Rs-198 ise tuza maruz kalmış topraklarda pamuk fidelerinin çimlenme oranını, gelişimini arttırmıştır [67]. Bu Pseudomonas türleri tuz stresine karşı koruyucular 
olarak hareket ederek, $\mathrm{Mg}^{+2}, \mathrm{~K}^{+}$ve $\mathrm{Ca}^{+2}$ emilimini arttırmış, $\mathrm{Na}^{+}$tutulumunu azaltarak, IAA üretimi ile bitkilerin gelişimine katkıda bulunmuşlardır [67]. Tuz stres koşullarında yetiştirilen yerfıstı̆̆ının bakteri suşları ile aşılanması, aynı koşullarda azot gübresi uygulamasından elde edilen sonuçlara benzerlik göstermiş ve araştırıcılar Paenibacillus alcaligenes, Bacillus polymyxa ve Mycobacterium phlei suşları, yüksek sıcaklık ve tuzlu koşullarda yer fistığı (Arachis hipogaea) büyümesini ve topraktan besin alımını olumlu yönde etkilediklerini açıklamışlardır [68].

PGPR mekanizmalarına sahip rizobakterilerin kirleticileri parçalayabilen ve kirlenmiş topraklarda bitki gelişimini mümkün kılan özelliklere sahip oldukları belirlenmiştir [69]. Siderofor, ACC-deaminaz ve fitohormonlar üreten Pseudomonas ve Bacillus suşları ile aşılanmış hint hardalı (Brassica juncea) bitkileri tarafından topraktaki nikel depolanabilmiştir [69]. Benzer şekilde Dimkpa ve ark. [46], Streptomyces acidiscabies'in bir suşu tarafından üretilen sideroforların, nikel ile kirlenmiş topraklarda, börülcenin (Vigna unguiculata) gelişmesine yardım ederek nikeli bağladığını açıklamışlardır. Pseudomonas, Azospirillum ve Rhizobium cinsleri, iyi bilinen PGPR potansiyelleri dışında, bakır kontamineli topraklarda yonca (Medicago sativa) tohumlarının koruyucuları olarak işlev görmüşlerdir [70].

\section{Bitki probiyotik bakteriler ve bitki hastalıklarının önlenmesi}

Bazı probiyotik bakterilerin, bitki patojenlerinin bazılarının gelişmesini engelleyen antibiyotik maddeleri sentezledikleri belirtilmiştir [24]. Örneğin, antibiyotik üreten Pseudomonas spp. suşu, buğdayda kök ve kök boğazı çürüklüğüne neden olan Gaeumannomyces graminis var. tritici'nin inhibisyonuna neden olmuştur [24]. Yüksek selenyum konsantrasyonlarına dirençli Klebsiella, Bacillus, Acinetobacter ve Paenibacillus cinslerinin farklı türleri, aynı patojenin biyokontrolünde etkili bulunmuştur [23]. Bacillus spp'ye ait çok sayıda suş, Gram-pozitif ve Gram-negatif bakterilere ve birçok patojenik fungiye karşı aktif olan antibiyotikler üretebilmiştir [26]. Bacillus cereus UW85, yoncada kök çürüklüğü kontrolünde etkili olmuştur [26]. Bacillus subtilis'in iki suşu, soya fasulyesi tohumlarını etkileyen çeşitli patojenlere karşı antibiyotikler üretebildiği gibi, bu bitkinin gelişimini ilerletmiştir [45]. Selülaz, kitinaz ve $\beta$ glukonaz gibi hidrolitik enzimler, patojenlerin biyokontrolünde önemli rol oynar, çünkü selüloz, kitin ve $\beta$-glukan, fungal hücre duvarının ana bileşenleridir. Kitinaz ve $\beta$-glukonaz salgılayan bakteriler, fungal gelişmeyi engellemişlerdir. Kumar ve ark. [71], Sinorhizobium fredii KCC5 ve Pseudomonas fluorescens LPK2'nin kitinaz ve $\beta$-glukonaz ürettiğini ve Fusarium tarafından oluşturulan hastalık şiddetini azalttığını bildirmişlerdir. 
Kitinaz ve $\beta$-glukonaz üreten bir Pseudomonas spp. suşu, dünyadaki birçok tarımsal ürünü en tahrip edici patojenlerden olan Rhizoctonia solani ve Phytophthora capsici'nin neden olduğu hastalıkları önlemede başarılı bulunmuştur [26]. Sellülaz üreten Micromonospora ve antibiyotik üreten Streptomyces'den oluşan kombinasyon, Phytophthora cinnamomi'nin neden olduğu kök çürüklüğünü baskılamıştır [72]. Pythium aphanidermatum'un neden olduğu, hıyar bitkilerinde damping-off (devrilme) hastalığının önlenmesinde sellülaz üreten Streptomycetes suşları etkili bulunmuştur [72]. Micromonospora sp., bitki probiyotiği olarak rapor edilmiş, Botrytis cinerea tarafından etkilenen domates bitkilerinde sistemik direnci indükleyebilmiştir [73]. Yapılan bir çalışmada, Pseudomonas'ın iki suşu ve mikoriza karışımının, domates bitkilerini kök-ur nematodlarına karşı koruduğu rapor edilmiştir [74]. Mikrobiyal sideroforlar, bitki gelişimini teşvik etme özelliklerinin yanı sıra, bitki patojenlerinin kontrolünde, fitopatojenler için ortamdaki mevcut demiri sınırlandırarak da önemli rol oynarlar [62]. Bu anlamda Pseudomonas siderophores, patates bitkilerinde Fuxarium oxysporum enfeksiyonunu kontrol etmiş, Pseudomonas ve Bacillus suşları ise mısır bitkilerinde çeşitli fungal patojenleri inhibe eden sideroforlar üretmişlerdir [62]. Yu ve ark. [75], Bacillus subtilis olarak tanımlanan bir siderofor üretici suşun, Fusarium solgunluğu üzerinde biyolojik kontrol oluşturduğunu ve biber gelişimini desteklediğini bildirmişlerdir. Verma ve ark. [12] neem ağacının (Azadirachta indica) rizosferinden izole edilen endofitik Streptomyces suşlarının, biyokontrol potansiyeli olan sideroforlar ürettiğini bildirmişlerdir. Fitoformon üreten bakteriyel türler aynı zamanda fitoplazmaya bağlı hastalıklar için uygun biyokontrol etmenler olarak belirlenmiştir [62]. Gamalero ve ark. [51], ACC deaminaz üreten Pseudomonas suşunun, bitkide fitoplazmalarının enfeksiyonu ile oluşan stresi azaltmada yardımcı olduğunu bildirmiştir.

Bazı probiyotik bakteri üyeleri patojenlere indüklenen sistemik yanıtı artırabilmiş ve tuzluluk gibi çevresel koşullara bağlı stresi hafifletmiştir. Örneğin, bitki probiyotik bakteri özelliklerini gösteren Stenotrophomonas maltophilia, buğday bitkilerinin tuz stresinden etkilenmeden gelişmesini sağlamıştır [33]. Borriss [17], Bacillus ve Paenibacillus 'un çeşitli suşlarının, soya fasulyesinde Rhizoctonia bataticola'nın neden olduğu kök çürüklüğünü önemli ölçüde azalttıklarını açıklamışlardır. Herrera ve ark. [76] buğday tohumlarından elde edilen Paenibacillus spp. ve Pantoea spp.'nin suşlarının, bitki probiyotik bakterilerinin özelliklerini gösterdiklerini açıklamışlar ve araştırıcılar bu suşları tek başına veya birlikte uyguladıklarında, buğday ve arpa danelerinde bulunan Fusarium graminearum'a karş1 etkili antagonistik özellikler gösterdiklerini tespit etmişlerdir. 


\section{Sonuç}

Günümüzde tarım; artan hayvancılık talebi ve artan insan nüfusunun ihtiyacını karşılamak için sürdürülebilir gıda ve yem üretimi, sınırlı kaynakların kullanılması (verimli topraklar gibi), geleneksel tarım uygulamalarından kaynaklanan yoğun çevresel sorunların giderilmesi gibi çeşitli zorluklarla karşı karşıya kalmaktadır. Bu sorunlar, gıda verimliliğini arttırmak için kimyasal gübre yerine organik gübrelerin (biyogübreler) uygulanması ile hafifletileceği gibi, bu amaçla yerli toprak organizmalarının keşfi ve kullanılması ile giderilecektir. Bu derlemede, son yıllarda yayınlanmış, bitki probiyotik bakterilerinin bitkilere olan potansiyel yararları ile ilgili çalışmalar özetlenmiştir. $\mathrm{Bu}$ yararlar, bitki patojenlerinin fito-uyarımı, besin mobilizasyonu ve biyokontrolünü içermektedir. Ayrıca, bu yararlı bakteriler, tuzluluk veya ağır metal birikimi gibi çeşitli faktörlerin oluşturduğu stresleri hafifletmeye yardımcı olmuşlardır. Bu nedenle, tek suşlarla formüle edilen biyogübrelerin veya farklı etkileri olan bitki probiyotik bakterilerin getirilerek uygulanması, ekosistemlerin korunması ve gida kalitesinin arttırılmas1 ile kimyasal gübrelere karşı olası bir çözüm olabileceğini göstermektedir. Sonuç olarak, bitki probiyotik bakterilerden oluşturulan etkili ve güvenli ürünlerin geliştirilmesi için tarım ile uğraşan araştırıcılar, politikacılar ve çiftçiler arasında bir iletişiminin oluşturulması, araştırma programlarının ve politikaların ortaya konması gerekmektedir. Bu durum sadece üreticiler için değil, aynı zamanda insan sağlığı ve dünyamızın temizliği içinde son derece önemlidir.

\section{Kaynaklar}

1. Garcia-Fraile, P., E. Menendez, and R. Rivas, Role of bacterial biofertilizers in agriculture and forestry. AIMS Bioengineering, 2015. 2: p.183-205.

2. Araus J, et al., Phenotyping and other breeding approaches for a New Green Revolution. Journal of Integrative Plant Biology, 2014. 56: p. 422-424.

3. Garcia-Fraile, P., et al., Rhizobium promotes non-legumes growth and quality in several production steps: towards a biofertilization of edible raw vegetables healthy for humans. PLoS One, 2012. 7: p. 1-7.

4. Flores-Felix, J.D., et al., Plants probiotics as a tool to produce highly functional fruits: the case of Phyllobacterium and vitamin C in strawberries. PLoS One, 2015. 10: p. 1-101.

5. Haas, D., and C. Keel, Regulation of antibiotic production in root-colonizing Pseudomonas spp. and relevance for biological control of plant disease. Annual Review Phytopathology, 2003. 41: p. $117-$ 153.

6. Kloepper, J., and M. Schrot, Plant growth-promoting rhizobacteria on radishes. Proceedings of the 4th International Conference on Plant Pathogenic Bacteria. France, 1978. 2: 879-882.

7. Hardoim, P.R., et al., The hidden world within plants: ecological and evolucionary considerations for defining functioning of microbial endophytes. Microbiology Molecular Biology Reviews, 2015. 79: p. 293-320.

8. Suzaki, T. and M. Kawaguchi, Root nodulation: a development al program involving cell fate conversion triggered by symbiotic bacterial infection. Currient Opinion in Plant Biology, 2014. 21:p. $16-22$. 
9. Pawlowski, K., and K.N. Demchenko, The diversity of actinorhizal symbiosis. Protoplasma, 2012. 249: p. 967-979.

10. Vessey, J.K., K. Pawlowski, and B. Bergman, Root-based N2-fixing symbioses: Legumes, actinorhizal plants, Parasponia sp. and cycads. Plant Soil, 2005. 274: p. 51-78.

11. Bhattacharyya, P.N., and D.K. Jha, Plant growth-promoting rhizobacteria (PGPR): emergence in agriculture. World Journal of Microbiology Biotechnology, 2012. 28: p. 1327-1350.

12. Vejan, P., et al., Role of plant growth promoting rhizobacteria in agricultural sustainability. Molecules, 2016. 21: p. 573-580.

13. Malua, E., and N. Vassilev, A contribution to set a legal framework for biofertilisers. Applied Microbiology and Biotechnology, 2014. 98: p. 6599-6607.

14. Tejera, N. et al., Isolation and characterization of Azotobacter and Azospirillum strains from the sugarcane rhizosphere. Plant and Soil, 2005. 270: p. 223-232.

15. Santi, C., D. Bogusz, and C. Franche, Biological nitrogen fixation in non-legume plants. Annals of Botany, 2013. 111: p. 743-767.

16. Nascimento, F.X., et al.,The role of rhizobial ACC deaminase in the nodulation process of leguminous plants. International Journal of Agronomy, 2016. 1: p.1-10

17. Borriss, R., Bacillus, a plant-beneficial bacterium, In: Principles of Plant-Microbe Interactions, 2015. Springer International Publishing, 379-391.

18. Jaiswal, D.K. et al., Potassium as an important plant nutrient in sustainable agriculture: a state of the art, In: Potassium Solubilizing Microorganisms for Sustainable Agriculture, 2016, Springer India, 21-29.

19. Velazquez, E., et al., Diversity of potassium-solubilizing microorganisms and their interactions with plants, In: Potassium Solubilizing Microorganisms for Sustainable Agriculture, 2016. Springer India, 99-110.

20. Sharma, S.B., et al., Phosphate solubilizing microbes: sustainable approach for managing phosphorus deficiency in agricultural soils. Springerplus, 2013. 2: p.587-592.

21. Bagyalakshmi, B., P. Ponmurugan, and S. Marimuthu, Influence of potassium solubilizing bacteria on crop productivity and quality of tea (Camellia sinensis). African Journal of Agricultural Research, 2012. 7: p. 4250- 4259.

22. Mishra, R.P., et al., Rhizobium-mediated induction of phenolics and plant growth promotion in rice (Oryza sativa L.) Current Microbiology, 2006. 52: p. 383-389

23. Duran, P., et al., Endophytic bacteria from selenium- supplemented wheat plants could be useful for plant-growth promotion, biofortification and Gaeumannomyces graminis biocontrol in wheat production. Biology and Fertility Soils, 2014. 50: p.983-990.

24. Ulloa-Ogaz, A.L., L.N. Munoz-Castellanos, and G.V. Nevarez-Moorillon, Biocontrol of phytopathogens: Antibiotic production as mechanism of control, In: Mendez-Vilas, A., The Battle Against Microbial Pathogens: Basic Science, Technological Advances and Educational Programs, 2015. 305-309.

25. Boudjeko, T., et al., Streptomyces cameroonensis sp. nov., a Geldanamycin producer that promotes Theobroma cacao growth. Microbes and Environments, 2017. 32: p.24-31.

26. Maksimov, I.V., R.R., Abizgildina, and L.I. Pusenkova, Plant growth promoting rhizobacteria as alternative to chemical crop protectors from pathogens. Applied Biochemistry Microbiology, 2011. 47: p. 333-345.

27. Taule, C., et al., The contribution of nitrogen fixation to sugarcane (Saccharum officinarum L.), and the identification and characterization of part of the associated diazotrophic bacterial community. Plant Soil, 2012. 356: p. 35-49.

28. Van Oosten, M.J., et al., Root inoculation with Azotobacter chroococcum 76A enhances tomato plants adaptation to salt stress under low N conditions. BMC Plant Biology, 2018. 18: p. 205- 211.

29. Chebotar, V.K., et al., Endophytic bacteria in microbial preparations that improve plant development. Applied Biochemistry Microbiology., 2015. 51: p. 271-277.

30. Grady, E.N., et al., Current knowledge and perspectives of Paenibacillus: a review. Microbial Cell Factories, 2016. 15: p. 203-217.

33. Singh, R.P., and P.N. Jha, The PGPR Stenotrophomonas maltophilia SBP-9 Augments Resistance against Biotic and Abiotic Stress in Wheat Plants. Frontiers in Microbiology, 2017.8: p. 1945-1960 . 
31. Sokolova, M.G., G.P. Akimova, and O.B. Vaishlya, Effect of phytohormones synthesized by rhizosphere bacteria on plants. Applied Biochemistry Microbiology, 2011. 47: p. 274-278.

32. Spaepen, S., Plant Hormones Produced by Microbes, In: Lugtenberg, B., Editor, Principles of PlantMicrobe Interactions, Switzerland: Springer International Publishing, 2015. p. 247-256.

34. Beneduzi, A., et al. Evaluation of genetic diversity and plant growth promoting activities of nitrogen-fixing bacilli isolated from rice fields in South Brazil. Applied Soil Ecology, 2008. 39: p. 311-320.

35. Liu, F., et al., Cytokinin-producing, plant growth-promoting rhizobacteria that confer resistance to drought stress in Platycladus orientalis container seedlings. Applied Microbiology Biotechnology, 2013. 97: p. 9155-9164.

36. Aloni, R., et al., Role of cytokinin and auxin in shaping root architecture: regulating vascular differentiation, lateral root initiation, root apical dominance and root gravitropism. Annals Botany, 2006. 97: p. 883-893.

37. Bent, E., et al., Alterations in plant growth and in root hormone levels of lodgepole pines inoculated with rhizobacteria. Canadian Journal of Microbiology, 2001. 47: p. 793-800.

38. Bakaeva, M.D., S.P. Chetverikov, and O.N. Loginov, The new bacterial strain Paenibacillus sp. IB-1: A producer of exopolysaccharide and biologically active substances with phytohormonal and antifungal activities. Applied Biochemistry Microbiology., 2017. 53: p. 201-208.

39. Asaf, S., et al., Bacterial endophytes from arid land plants regulate endogenous hormone content and promote growth in crop plants: an example of Sphingomonas sp. and Serratia marcescens. Journal of Plant Interactions, 2017. 12: p. 31-38.

40. Ghosh, P.K., S.K., Sen, and T.K. Maiti, Production and metabolism of IAA by Enterobacter spp. (Gammaproteobacteria) isolated from root nodules of a legume Abrus precatorius L. Biocatalysis and Agricultural Biotechnology, 2015. 4: p. 296-303.

41. Flores-Felix, J.D., et al., Use of Rhizobium leguminosarum as a potential biofertilizer for Lactuca sativa and Daucus carota crops. Journal of Plant Nutrition and Soil Science, 2013. 176: p. 876882.

42. Flores-Felix, J.D., et al., Rhizobium as plant probiotic for strawberry production under microcosm conditions. Symbiosis, 2015. 67: p. 25-32.

43. Yanni, Y.G., et al., Assessment of the natural endophytic association between Rhizobium and wheat and its ability to increase wheat production in the Nile delta. Plant Soil, 2016. 407: p. 367-383.

44. Kong, Z., et al., Effects of 1-aminocyclopropane-1-carboxylate (ACC) deaminase-overproducing Sinorhizobium meliloti on plant growth and copper tolerance of Medicago lupulina. Plant Soil, 2015. 391: p. 383-398.

45. Araujo, F.F., A.A. Henning, and M. Hungria, Phytohormones and antibiotics produced by Bacillus subtilis and their effects on seed pathogenic fungi and on soybean root development. World Journal of Microbiology and Biotechnology, 2005. 21: p. 1639-1645

46. Dimkpa, C., et al., Hydroxamate siderophores produced by Streptomyces acidiscabies E13 bind nickel and promote growth in cowpea (Vignaunguiculata L.) under nickel stress. Canadian Journal of Microbiology, 2008. 54: p. 163-172.

47. Khan, A.L., et al., Bacterial endophyte Sphingomonas sp. LK11 produces gibberellins and IAA and promotes tomato plant growth. Journal of Microbiology, 2014. 52: p.689-695.

48. Magnucka, E.G., and S.J. Pietr, Various effects of fluorescent bacteria of the genus Pseudomonas containing ACC deaminase on wheat seedling growth. Microbiological Research, 2015. 181: p.112119.

49. Zahir, Z.A., et al., Comparative effectiveness of Pseudomonas and Serratia sp. containing ACCdeaminase for improving growth and yield of wheat (Triticum aestivum L.) under salt-stressed conditions. Arch Microbiol., 2009. 191: p. 415-424.

50. Ghavami, N., et al., Effects of two new siderophore producing rhizobacteria on growth and iron content of maize and canola plants. Journal of Plant Nutrition, 2016. 40: p. 736-746.

51. Gamalero, E., and B.R. Glick, Bacterial modulation ofplant ethylene levels. Plant Physiology, 2015. 169 : p. 13-22. 
52. Brigido, C., et al., Expression of an exogenous 1- aminocyclopropane-1-carboxylate deaminase gene in Mesorhizobium spp. reduces the negative effects of salt stress in chickpea. FEMS Microbiol Letters, 2013. 349: p. 46-53.

53. Glick BR (2014) Bacteria with ACC deaminase can promote plant growth and help to feed the world. Microbiol Research, 169: 30-39.

54. Shaharoona, B., et al., Fertilizer-dependent efficiency of Pseudomonas for improving growth, yield, and nutrient use efficiency of wheat (Triticum aestivum L.). Applied Microbiology and Biotechnology, 2008. 79: p. 147-155.

55. Zerrouk, I.Z., et al., A Pseudomonas strain isolated from date- palm rhizospheres improves root growth and promotes root formation in maize exposed to salt and aluminum stress. Journal of Plant Physiology, 2016. 191: p. 111-119.

56. Suarez, C., et al., Plant growth-promoting effects of Hartmannibacter diazotrophicus on summer barley (Hordeum vulgare L.) under salt stress. Applied Soil Ecology, 2015. 95: p. 23-30.

57. Dastager, S.G., C.K. Deepa, and A. Pandey, Isolation and characterization of novel plant growth promoting Micrococcus sp NII-0909 and its interaction with cowpea. Plant Physiology and Biochemistry, 2010. 48: p. 987-992.

58. Panda, P., S. Chakraborty, and D.P. Ray, Screening of phosphorus solubilizing bacteria from tea rhizosphere soil based on growth performances under different stress conditions. International Journal of Biological Sciences, 2016. 3: p. 39-56.

59. Şahin, F., R.Çakmakçı, and F. Kantar, Sugar beet and barley yields in relation to inoculation with N2 fixing and phosphate solubilizing bacteria. Plant and Soil, 2004. 265: p. 123-129.

60. Sangeeth, K.P., R.S. Bhai, and V. Srinivasan, Paenibacillus glucanolyticus, a promising potassium solubilizing bacterium isolated from black pepper (Piper nigrum L.) rhizosphere. Journal of Spices Aromatic Crops, 2012. 21: p. 118-124.

61. Zhang, C., and F. Kong, Isolation and identification of potassium solubilizing bacteria from tobacco rhizospheric soil and their effect on tobacco plants. Applied Soil Ecology, 2014. 82: p.1825.

62. Saha, M., et al., Microbial siderophores and their potential applications: a review. Environmental Science and Pollution Research, 2016. 23: p. 3984-3999.

63. Verma, V.C., S.K. Singh, and S. Prakash, Bio-control and plant growth promotion potential of siderophore producing endophytic Streptomyces from Azadirachta indica Juss. Journal of Basic Microbiology, 2011. 51: p. 550-556.

64. Karagöz, K., et al., Characterization of plant growth promoting traits of bacteria isolated from the rhizosphere of grapevine grown in alkaline and acidic soils. European Journal of Soil Biology, 2016. 50: p. 144-150.

65. Wang, W., B. Vinocur, and A. Altman, Plant responses to drought, salinity and extreme temperatures: towards genetic engineering for stress tolerance. Planta, 2003. 218: p. 1-14.

66. Liddycoat, S.M., B.M. Greenberg, and D.J. Wolyn, The effect of plant growth-promoting rhizobacteria on asparagus seedlings and germinating seeds subjected to water stress under greenhouse conditions. Can J Microbiol., 2009. 55: p. 388-394.

67. Paul, D., and S. Nair, Stress adaptations in a Plant Growth Promoting Rhizobacterium (PGPR) with increasing salinity in the coastal agricultural soils. Journal of Basic Microbiology, $2008 . \quad$ 48:p. 378-384.

68. El-Akhal, M.R., et al., Effects of salt stress and rhizobial inoculation on growth and nitrogen fixation of three peanut cultivars. Plant Biol (Stuttg), 2013. 15: p. 415-421

69. Ma, Y., M. Rajkumar, and H. Freitas, Isolation and characterization of Ni mobilizing PGPB from serpentine soils and their potential in promoting plant growth and $\mathrm{Ni}$ accumulation by Brassica spp. Chemosphere, 2009. 75: p. 719-725.

70. Carrillo-Castaneda, G., et al., Plant growth-promoting bacteria promote copper and iron translocation from root to shoot in alfalfa seedlings. Journal of Plant Nutrition, 2002. 26: p. 1801- 1814.

71. Kumar, H., V.K. Bajpai, and R.C. Dubey, Wilt disease management and enhancement of growth and yield of Cajanus cajan (L) var. Manak by bacterial combinations amended with chemical fertilizer. Crop Protection, 2010. 29: p. 591-598. 
72. El-Tarabily, K.A. Rhizosphere-competent isolates of streptomycete and non-streptomycete actinomycetes capable of producing cell-wall-degrading enzymes to control Pythium aphanidermatum damping-off disease of cucumber. Canadian Journal of Botany, 2006. 84: p. 211222.

73. Martínez-Hidalgo, P., J.M. Garcia, and M.J. Pozo, Induced systemic resistance against Botrytis cinerea by Micromonospora strains isolated from root nodules. Frontiers in Microbiology, 2015. 6: p. 111

74. Sharma, I.P., and A.K. Sharma, Effective control of root-knot nematode disease with Pseudomonad rhizobacteria filtrate. Rhizosphere, 2017. 3: p. 123-125.

75. Yu, X., et al., The siderophore-producing bacterium, Bacillus subtilis CAS15, has a biocontrol effect on Fusarium wilt and promotes the growth of pepper. Eurepan Journal of Soil Biology, 2011. 47: p. 138-145

76. Herrera, S.D., et al., Wheat seeds harbour bacterial endophytes with potential as plant growth promoters and biocontrol agents of Fusarium graminearum. Microbiological Research, $2016 . \quad$ 186: p. 37-43. 